\title{
The future of the apple growing branch in Hungary
}

\author{
Gonda, I., Apáti, F. \\ Centre for Agricultural Sciences and Engineering, University of Debrecen \\ 138 Böszörményi St., 4032 Debrecen, Hungary
}

Summary: The present study deals with the actual situation of the Hungarian apple production in order to outline the chances of the future and the trends of the development to be anticipated. The general conclusion is accepted that on the long run Hungarian apple production ought to be reorganised. The conditions of keeping the position on the international market are outlined. The main concern is the aging of the plantations, i.e. $40 \%$ of them being more than 25-30 year old, and produce apple being suitable for processing only. Organisation of growers is rudimentary, export markets are limited, and buyer's market is everywhere dominant and is getting more severe. All those circumstances anticipate the reduction of the apple growing branch from the present 35000 hectares to 15-20 000 hectares within a period of less than 10 years.

Key words: Hungarian apple growing, apple branch, competitiveness

\section{Introductoin}

\section{The last one and half decade: consolidated constancy}

Many studies and strategic projects prepared by expert institutions, organisations, business federations, etc. dealt with it repeatedly, through nearly two decennia. Most of them reflected the spirit of the plan of People's Republic. They expressed the desires as directives, how many apples are necessary for fresh consumption, for industrial processing, what should be the extent of plantations, how the consumption should be changed, what are the aims of production policies, etc.? The question has never approached from side of the market, what is the demand along the season of consumption, at the dates of harvest and subsequently during storage? We cannot find any sign of taking into consideration the market, the only decisive moment of policies nowadays.

What happened during the last fifteen years to improve the adverse conditions of the apple-growing branch?

- The plantations grew old being maintained one year after the other reproducing all the problems and dragging along the dismal burdens.

- The ensemble of growers has been polarised gradually as the whole society (a small fraction of the society enjoying favourable infrastructure and growing sites survived, whereas the small owners became looser of the severe competition).

- Opposed to the obviously rallying of the merchants, the society of growers, without organisation has been delivered without reasonable possibility of selfesteem.
- The association to the European Union induced and brought to light a couple of problems and contradictions (the disposition and direction of marketing channels, appearance of new limits of quality, etc.).

- Incompetence and restrictions of professional (business federations, safeguarding of interests) organisations.

- Increasing frequencies of fiascos due to global climatic changes, marketing failures.

This is only a small sample of the prevailing distress. The rest will be the topic of the following study. We do not want to analyses the details of the story, but concentrate on the most important moments (faculties and difficulties) and explore the possible ways out from the pit.

\section{The status of the markets and tendencies observed along the international happenings}

The world's apple production is claimed to be 60-65 million tons. Substantial part, more than half of it comes from Asia, the second largest producer is Europe with one quarter of the volume (Figure 1). On the worldwide level, apple production is a vigorously increasing branch with an increment of $2-4 \%$ per year due to developing countries (China, India, Iran, Turkey, South-America), whereas the production is stagnant or declines in most countries of Europe. The increment of the offer exceeds that of the demand, which means a buyer's market or overproduction, which tends to increase in the future. The developing countries will appear as serious competitors on the European markets. 


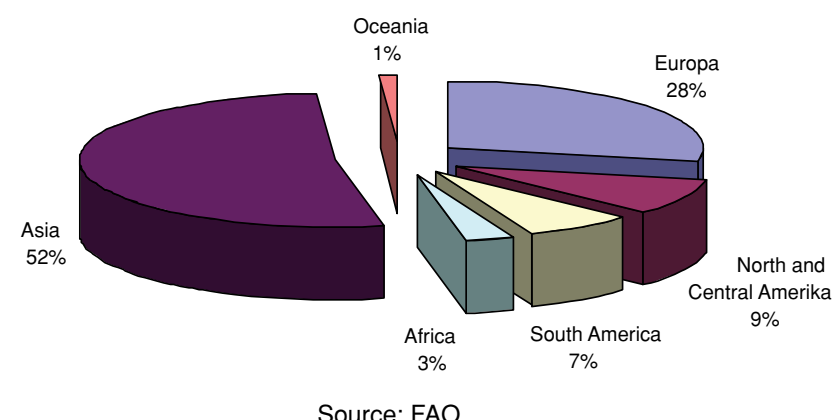

Source: FAO

Figure 1: Distribution of apple production of the world (2005)

The most dynamic increment is experienced in China, where the growth doubled the volume between 1994 and 2000. More recently, however, the statistic shows stagnation. China alone produces now 20 million tons, one third of the world's total. In spite of that, it will not cause concern on the European market within the next 5-10 year period especially regarding apples for fresh consumption. The underdeveloped storing and packing and the high rate $(70 \%)$ of the fraction bound to processing and the large demand of the East Asian and Oceania market (a population of 2 billion). However, since about ten years, the apple concentrate exported broke down the prices of the market. They produce the apple under extremely extensive conditions at very low costs, therefore, keep the prices on a baffling low level with their profuse offer (one $3^{\text {rd }}$ of the world's volume). This fact is a valid brake of improving the economic conditions in Hungary too.

European apple production is also decisive with more than $4^{\text {th }}$ participation in the world's contingent (16-18 million tons). Nearly 2/3 part of it is produced by the EU states. Former, during the period of EU-15 states, the volume was 7-8 million t/year, and with 2004, it increased to 10-12 million tons due to the joining of Poland and - at a lower rate - of Hungary.

Figure 2 shows the participation of states within the EU27 in the apple production of the region. Hungary is represented by $5 \%$.

The leading producers of apple within the EU, regarding the quantity, are Poland and Italy. The three main states Poland, Italy and France - produce $60 \%$ of the volume. However, we should remark that Italy, France and Germany sell $70-80 \%$ of the volume for fresh consumption, whereas this fraction is in Poland 20-30\% only. Further difference is

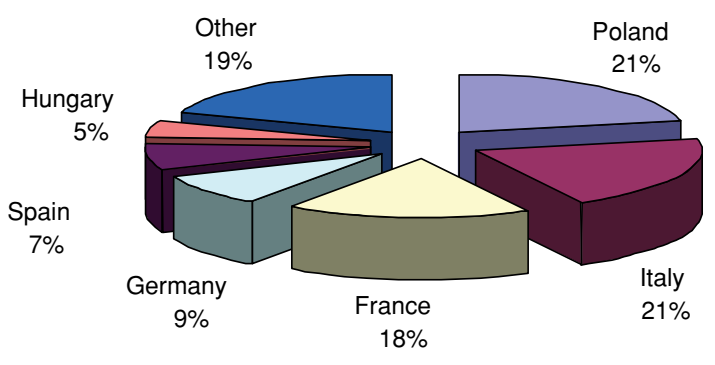

Source: Eurofel

Figure 2: Participation of the main apple growing states of EU-27 (2005) observed, in two last mentioned countries, that the age of plantations is very high (30-40\%) and the ratio of up to date intensive orchards is low (10-20\%). During the past years, Poland exerted serious influence on the European apple market, as we may regard on Poland as on the China of Europe. Although the rate of apple for fresh consumption is only $20-30 \%$, but the quantity (600-800 thousand tons) is 3-4-times higher than the Hungarian and almost equal with that produced by South-Tyrol. The problem of the European market is that the apple is offered on very cheap price - the real cause of it is not clears - which is decisive on the European level. The pressure on the EU market of apple juice is even more severe as 1.5-2.0 million tons of industrial apple is almost the half of the total volume (!) produced in the EU.

\section{The economic-marketing situation in Hungary and the expected tendencies}

Apple production is the most significant (about 60\%) branch of fruit growing branch in Hungary. During the last 20 years, the decline was substantial (Figure 3), at present on 35000 ha, 400-600 thousand tons are produced grown yearly.

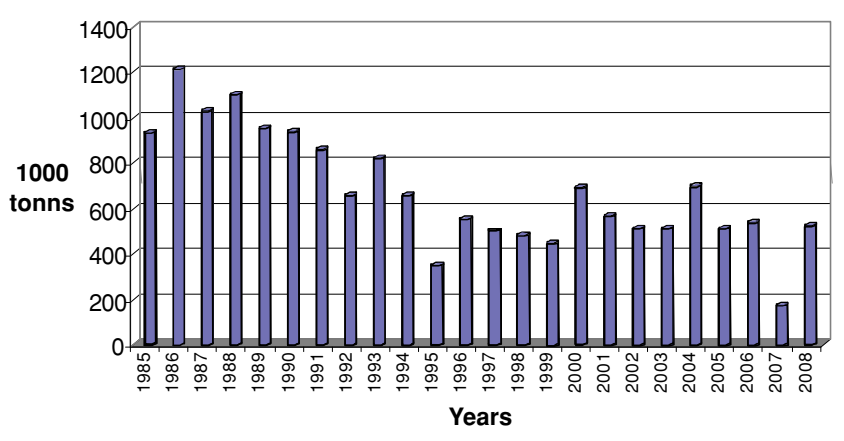

Source: KSH (2008: preliminary data)

Figure 3: Apple production of Hungary during the period 1985-2008 (thousand tons)

A regretful tendency is the increasing rate of industrial utilisation and the decline of the fresh consumption, i.e. $70-80 \%$ of the volume is processed for juice.

Explanation: Northern Great Plain 69\%, southern Great Plain $8 \%$, Central Hungary 6\%, Central Transdanubia 3\%, Western Transdanubia 6\%, South Transdanubia 3\%, North Hungary $5 \%$

It is unequivocal that more than $2 / 3$ of the volume is coming from the Northern Great Plain (Figure 4), mainly the country Szabolcs-Szatmár-Bereg alone. Which gives about the half part.

Let alone production, domestic consumption does not show advantageous traits. The existing picture shows about 15-20 kg/person/year consumption, though exact statistics are lacking. By all means, the level sank from 30 $\mathrm{kg} /$ person/year, as being estimated during the years of 1980 years. One of the causes is the declining living standard, but 


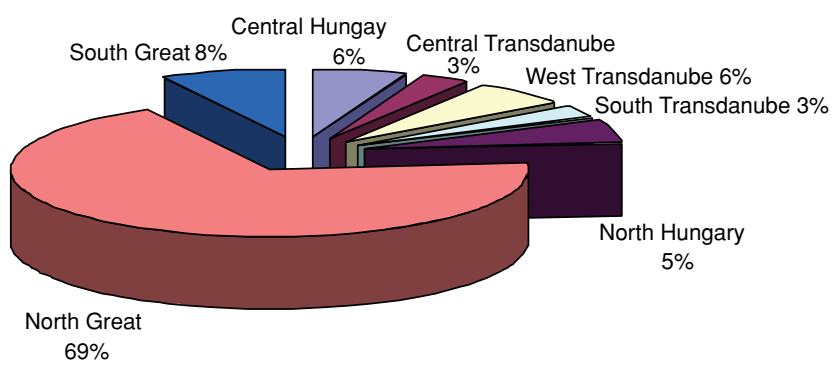

Source: KSH

Figure 4: Regional distribution of apple growing in Hungary (means of 2000-2005)

the increasing trade of southern fruits available in the shops all year around, being a concurrence of apple on the market, is significant. Thus the home produced apple is exposed to the competition of fruit market of the whole world.

Foreign trade (export-import) of the Hungarian apple declined significantly. In the 80-es, the export of 300-500 thousand tons, declined to a few thousand tons in early 2000 , but increased a little with the accession to the EU without attaining some 10 thousand tons. The tendency is essentially negative. The present situation cannot be compared with that of the 80-es because since than the whole social structure and market changed radically.

For dealing with questions of trade and consumption, we have to consider the increasing tendencies experienced by the expansion of hyper-super markets at the expense of the small shops. In West-European countries, the rate of the former is $50-60 \%$, whereas in contemporary Hungary 30-40\%, which is decisive in transforming the balance of powers. The chainmarkets require large quantities, uniform quantities, arbitrary dismounting and packing, almost limitless choice of varieties, exact delivery within 24 hour terms. Small farms cannot fulfill all that; and only few of the cooperatives (TÉSZ) are able to meet those expectations. As a consequence, the importance of wholesale markets diminished (though nevertheless their influence is far from being negligible), and the initiatives to form grower's organisations received a valid impetus. We have to emphasise that it is not for the interest of hypermarkets but rather of the growers because if Hungarian suppliers are lacking, the markets will look for foreign resources within reach. Continuous supply is the weak point of the Hungarian growers, which is the main reason of the relatively poor representation of home grown apples in the trade. The responsibility of this failure is up to the incapacity of growers to become organised.

\section{Evaluation of Hungarian apple growing (the past and the present)}

\subsection{Ecological conditions of growing sites}

Ecological conditions of apple growing in Hungary, compared with European terms could be judged as mediocre. Related to a theoretical optimum (being $800 \mathrm{~mm} /$ year), the lack of precipitation and low air humidity, moreover, weather excesses (occasional frost damages in autumn, winter and spring, atmospheric drought, etc.) risk the yield. During the last 15 years, it was proved that intensive, high density plantations on dwarfing stocks are able to produce 40-45 t/ha yields of good quality, obviously, on prosperous sites. Unfortunately, less productive plantations are found on mediocre and poor growing sites. The choice of the site is by all means a significant criterion of success.

In the west to Hungary, the main competitors produce apple with less risk (South-Tyrol, Boden Sea) where the 60-70 t/ha yields and excellent quality are obtained regularly. Our competitiveness in relation to these regions is low. The high biological value is associated with the one month longer growing period (earlier spring and later leaf fall), and the higher air humidity during the summer. The stress factors are less severe, in addition to that technical means facilitate the prevention or mitigation of losses (nets for hail, anti-frost irrigation, etc.).

The continental type of climate in Hungary, frosts and atmospheric droughts threaten the yield of some years, therefore the means are hardly exceeding 30-40 t/ha as maxima. This does not mean that sometimes $60 \mathrm{t} / \mathrm{ha}$ could not be achieved under intensive cultivation. That happens actually in the near past, however, followed by disappointingly low yields, i.e. the continuity - being also important - was poor. As a consequence of global climatic changes, the frequency of weather excesses increased substantially, which endangers the rentability as well. The technical prevention ought to be considered as an actual possibility to increase the viability of apple production.

The choice of the growing site is o prime importance within the possible scope of circumstances. This principle is profusely documented by the grate variation of yield and quality among the plantations existing. Unfortunately, many of the young plantations are doomed to failure from the very beginning. Most mistakes are found on the bottom of valleys, where the water table is high, temporary flooding occurred, night frosts are frequent, on the other hand, the soil quality is poor and variable, the tilth is shallow. The pity is that after 1995, also many plantations made with state subvention are confronted with similar problems. The responsibility is up to the organs (persons), which agreed with the project on the spot. During the 1970-80-es, perambulation of the planned plantations was compulsory in order to prevent mistakes. Former, a state undertaking for planning orchards, research institutes, stations and local authorities were competent to decide in questions of investments requiring state support. It happened often that unfounded expenses were prohibited. As an urgent necessity, the money of taxpayers should be watched closely with high priority.

\subsection{The status of Hungarian plantations as a basis of the branch}

The conscription of 2007 registered 34900 hectares in 14621 individual apple plantations in Hungary. Compared 
with the data of the 2001 census, about 8000 hectares, i.e. 5-6 thousand plantations have been abolished during 6 years. The majority of them were small, few hectares and aging (more than 20-25 year old). Between 2001 and 2007, less than 2000 ha of new plantations are made, which is compared with the former 6 years, i.e. 1999-2004, (about 10 thousand hectares), the inclination of planting declined conspicuously.

Instead of going into details, we emphasise the heaviest concern of apple growing branch, the role of the rate of neglected plantations.

Referring to the 34900 ha apple plantations mentioned, we have to distinguish three parts of nearly equal thirds of apple plantations:

- 13000 hectares (nearly one $3^{\text {rd }}$ of the surface) are more than 25 old, age-worn plantations in a strict sense of the words. As estimated, about 8-10 thousand hectares are relatively neglected, and seem to be older than indicated, i.e. in poor condition and there are many trees missing.

- The other extreme, younger than 10 years, planted between 1998 and 2003 (sponsored mainly by state subvention), and are "intensive" or "semi-intensive" orchards with dense planting design. Their rate is equally one $3^{\text {rd }}$, about 11000 hectares. The estimated fraction, more than 2-3 thousand hectares, is already neglected due to the adverse market conditions under-motivated.

- The group of intermediate age (also about 11000 hectares), i.e. 10-25 year old, is also endangered, as 2-4 thousand hectares are in a "critical state" regarding their condition.

Summing up the three thirds of plantations, on $\boldsymbol{a}$ countrywide level there are 12-17 thousand hectares being inadequately managed if not neglected. Consequently, the following concerns are met and have to be satisfied:

- Apple juice is produced of 100-120 thousand tons, a quantity, which is a fraction only of $25-40 \%$ of the yield of 300-400 thousand tons of apple bound for processing. That means, it is sold at a low price, and causing overproduction on the market leaving the producers without any income.

- The market of apple for fresh consumption is also impaired heavily because the volume of 10-20 thousand tons of fresh apple with low quality appearing in autumn causes depression of the prices of the high quality apple for fresh consumption.

- During the last five years (2005-2009), subventions of 1.5-2.0 billion Ft have been "swallowed" as based on the growing area (SAPS) and called "AKG", although they did not earn economic benefit. The money was lost for the national budget.

- Diseases and pests emerged on the neglected orchards impairing the health of properly treated plantations in the neighbourhood.

For the reasons above mentioned we have to use all possible means to abolish the neglected and abandoned plantations. Growers ought to be moved by punitive sanctions, as subventions for eradication will not be paid in the future. Otherwise, the desired process will be delayed, which is inadmissible from the point of view of the branch. The lack of determined action will cause more damage, and more growers will give up than in a clean situation, in spite of many may suffer initially under the pressure.

\subsection{System of cultivation, utilisation of varieties and rootstocks}

After the change of regime, the new, intensive plantations use less variable rootstocks. Semi-dwarfing (M26) and dwarfing (M9) stocks prevail; only a small fraction uses medium vigorous stocks (MM11).

During the last fifteen years, semi-dwarfing rootstocks have been preferred to planting designs with 550-2500 tree/ha density, which means semi-intensive or intensive plantations appeared. More than 1500 trees/ha need a mechanic support system, which increases the costs substantially. Irrigation systems have not been always claimed in the technology, unfortunately, which would be an important condition of quantity as well of quality. It is highly probable that after the end of the crisis, in the future, 2000 or more trees per hectare will be planted in Hungary. This would be a lucky compromise, an optimum between yields, quality and manual labour.

In the early 2000s, a couple of new varieties substitute the formerly dominant Variety 'Jonathan'. Accumulated experiences caused the diminution of the assortment; practically 4 or 5 varieties and their mutants have been maintained (Idared, Jonagold, Golden Delicious, Gala, Pinova). The initial dominance of Idared declined because of causing problems. The reduction of varieties used in plantations is a worldwide phenomenon extending to the southern hemisphere too. The reason of it is the claim to work with large quantities of uniform quality in the trade. Consequently, the worldwide preferred varieties are: 'Red Delicious', 'Golden Delicious', 'Gala', 'Granny Smith', 'Jonagold'. Further extension of the list is not expected, which means that the Hungarian assortment should maintain the same choice.

The so-called "club varieties" do not much influence the tendencies of the world markets, and remain rather local. They touch us neither. The use of varieties will be much subject to global information through the trading processes.

\subsection{Conditions of the market, sales and prices}

The market of apples is a typical example of excessive uncertainties due to variation between years in prices and security of sales.

In the price of apple for processing, we may state that during the last twenty years, no increment of prices could be detected. In most of the years, the price kept to be low, oscillating between $10-20 \mathrm{Ft} / \mathrm{kg}$. Once in 3-4 years, outstanding peaks (30-40 Ft/kg) may occur, which was generally due to some anomalies on the world market. It is also of interest that within the season of 2-3 months, there is 
no variation of prices; they are determined for a whole season. In this year, the producer's price of industrial apple was around $10 \mathrm{Ft} / \mathrm{kg}$, which is merely the proof of an unprofitable business.

The market of apple for fresh consumption was after the accession to the EU, in two seasons, 2003/04 and 2004/05, very weak, however, in two subsequent seasons relatively good (2005/06, 2006/07) with acceptable prices. 2007/08 produced unexpected high prices due to the severe (total) frost damages in the spring of 2007, which was coupled with extremely low yields, so that prices reflected the offer of imported apple. In 2008/09, the profuse yields caused the break down of prices, which contrasted with the "record prices" of the former season. Even more depressive was the "idle" market in the autumn of 2009. The unequivocal within-season oscillation in the prices of apple varieties of summer and autumn maturity was a phenomenon experienced yearly. Consequently, the prices are relatively prosperous until early September, but drop precipitously and remain low until December-January, as the temporary store become exhausted the stock of "cheap" apple. Afterwards, the prices increased continuously and are higher than the seasonal means. Only the trade of the cooled stores is able to enjoy the advantages of this period.

The market of the fresh consumed apple was impaired by a tendency lasting since several years. It happened earlier too that the stores in Western Europe were not depleted until the end of the season, but no large stocks of unsold apple accumulated. The large volume of offer caused low buying up prices, down to $40-60 \mathrm{Ft} / \mathrm{kg}$. The problem is even larger that consumption also declined, which is reflected by the number of merchants as ell as transactions. A large fraction (20-30\%) of the yield in NW-Hungary was sold "non officially" in neighbouring Rumania. In 2009, this channel got plugged almost entirely due to the lack of demand and also to the aggravated prohibition of Rumanian import rates. Those caused also the decline of disposition of production, substantially.

\subsection{Organisation of the production and the background of market}

The main difficulty mentioned already repeatedly was the reluctance of the growers to join into organisations, which is also reflected by the Production and Selling Organisations (TÉSZ), which are still poorly off. Practically, there is no TÉSZ on the list, which would be able to deliver regularly volumes of adequate quality. The cause of that is partly the too large number of organisations, which dissipate the capacities, but they cannot find volumes of goods, lack of growers to sell produce (which prefer to sell for the consumers directly, not through the TÉSZ organisations). Very often even members of the TÉSZ themselves sell their goods behind the TÉSZ. But the lack of capital was a permanent difficulty. The weakness of TÉSZ organisations is proved by the fact that the rate of their transactions dealing with vegetables and fruits amounts $18-20 \%$ instead of the reasonably expected 50-60\%. Some Grower's Organisations dispose with some thousand, occasionally ten times more tons of apples, compared with the western organisations with 100-200 thousand tons at least. Moreover, in South-Tyrol, they produce 1 million tons and there are two organisations only dealing with that quantity.

The crises of the last years are due largely to the lack of organised interventions from the side of growers. We ought to hope that the outstandingly catastrophic season of 2009 will awake the growers who survived the crisis and still want continue and start organising themselves.

Not only the growers are responsible for the lack of confidence in the organisations. The story begins with the early 2000 years when the formation of TÉSZ organisations started. Most of them was initiated by merchants of trading enterprises, and renamed simply their shop to TÉSZ, took as members some of their friends and former customers and did not want to give up their independence. Everything has been continued as earlier under the new name. Practically, no control of the growers as members could be exercised, the only purpose was to demand subventions asked from the state. The contrasting interests between growers and tradesmen have been conserved; no advantage for the producer was evident. The utilisation of the subventions was loosely supervised, and seemingly much of them were spent for unknown purposes. An eloquent testimony of the process is the fact that after the accession to the EU, the number of TÉSZ organisations being nearly hundred, declined to its half. Most likely, the EU subventions are controlled rather closely, so the initiators did not find their interest, i.e. they were not motivated to continue. According to our opinion, the radical decline of the number of TÉSZ organisations (and the feebleness of the Hungarian origination) is due much more to the commercial interests of some tradesmen than to professional considerations or fusions.

The real paradox is not if tradesmen organise a TÉSZ, as it happened in Germany, where during the 1960-1970 started an organisation, which is still alive and successful. The tradesman had relations to the market, knew the growers personally and disposed of marketing experiences. He was a potent initiator. The interest of the tradesman is not a disadvantage provided the common interests and mutual advantages are recognised and the principle of "live and let live" will be a benefit of both parties. As long as everybody will strive for his interests on the short run, and wants only to exploit the other, no vital organisation could arise. We are of the opinion that in Hungary a serious change of attitudes is highly needed for the organisation of growers and tradesmen.

For a TÉSZ organisation initiated by the growers a dismal example is given in county Szabolcs, where the common interest of the merchant as a concern was beyond question. The management was authorised by the growers, but supposedly, they mismanaged the common property, by weak responsibility and poor competence. They had other motivations and their decisions caused insolvency of the organisation. Several hundreds of supplier lost their money. The news of the scandal spread over the whole county, 
spoiled the confidence of the growers. After this incident, it is difficult to prove that the organisation is necessary and the TÉSZ could be a good idea!

At any case, the basic problem is the lack of common interests and confidence between tradesmen, growers and managements. That's because the members of the organisation often sell their produce avoiding the official way through the TÉSZ, because he wants to see his money immediately. Nevertheless, as long the organisation cannot dispose of a safe basis of merchandises, cannot build up a position on the market, and as long it has not a secure market, the lack of confidence will not allow to build up a safe basis of merchandises, and the circle is closed, the story begins again.

\subsection{Direction of the branch, business federation, protection of interests}

The professional organisations of the branch (council of production, society) were entirely "devotees of the apple juice", i.e. processing apple during the fifteen years of existence. They fought exclusively for the subvention of the juice and for the sum of the subvention. Never occurred that the apple for fresh consumption was mentioned or its business federation should be organised, moreover, the stimulation of apple growing with higher quality and to increase that line of activities, promotion of building up a basis of commodities to help the export and make it competitive. For a certain degree, their argument is acceptable; they followed social political aims but conserved the position attained since decades. They wanted to help hundreds of growers and their families, but stabilised their status on a sub-optimal level.

We have to recognise the generous efforts for the sake of defend the "successful" activity of juice producers, especially if compared with unemployment due to the abolition of coalmines and metallurgic plants. The apple branch should have better perspectives.

\subsection{Research, Development, extension service}

Hungarian fruit growing industry exists for more than 150 years; the positive role of research institutes and teachers in founding conditions is out of question. Those institutions are now in difficult situation as the state abandoned its maintenance; moreover, their sale is anticipated. Many young experts are bound as replacement but do not find a job. Precious assortments and stocks of varieties and collections are threatened as biological basis of progress. The competition is severe worldwide, new varieties are bred and adopted, technologies tested and developed in order to reduce the production costs and maintain the best quality. All that makes dubious the rationality of governmental attitudes.

In the past, we know about several attempts, which strived for the establishment of professional extension activities (ministry, higher education, research institutes, network of village-husbands, etc.) with countrywide or regional competence. Not a single attempt earned recognition. This is a mere handicap in the comparison with other countries, where the information of the farmers is held up to date. The single farmer is delivered to accidental information and cannot cope with the complicated municipal regulations, let alone the daily news about the market. Thus the production and sale of delicate quality and perishable commodities means insurmountable difficulties.

\subsection{The function of the system of subventions}

Among the weaknesses of the system of management the distribution of subventions is one of the most susceptible. The support of investments by the EMVA is expected to become reliable since the accession to the EU for a long run - actually for the period 2007-2013 - through even years in order to planning safely. Its realisation happened to meet some obstacles. Subventions of planting have been announced twice during the four-year-period (2007-2010) though it was expected every year. Even more important is that the criteria proclaimed by the tenders varied yearly, which made the competition entirely incalculable and those frustrate the planning for the short as well as for the long run. Under the present conditions, nobody as competitor may know whether he will fulfil expectations at the next term.

The situation is aggravated by the delay of payments for irrationally long terms, which endangers the liquidity on enterprises (e.g. the sums payable for planting in the spring and autumn of 2008 are still pending in October 2009). A remarkable appearance of concepts of the professional management aiming to speed up the reconstruction of plantations is expressed by the fact that since the beginning of January 1, 2007 (the start of the EU cycle - 7-year-plan) not a single stiver has been paid for supporting plantings.

The system of subvention is hectic and incalculable; therefore many enterprises renounced of participate in the completion and got uncertain.

\section{Outlooks of the future}

Up to now, we attempted to describe and evaluate the present situation. Now we are decided to make a draft on the future and anticipate the expectations of the market, mainly producer's prices, securities and concurrences.

Summing up, what happened in the near past in Hungary, in the society of growers, in the trade and in the professional management, we have to state simply, the majority of the apple (producing)- growing branch is far from being competitive under the present and future conditions of the market.

The responsibility of the considerable of the direction of the branch - and the representatives of several above named - organisations, which supported and stabilised the apple juice industry, in other words the growing of industrial apple. As a result, plantations doomed to grow industrial apple received subvention survived instead of striving for higher quality, i.e. apple for fresh consumption. Already 10 years ago, warnings have been published within and beyond the country's boundaries that industrial apple growing will 
soon experience heavy economical difficulties. It was obvious that the producer's prices are highly variable and tend to diminish inevitably (China and other developing countries increase their export and cause overproduction on the world). The security of apple juice is further impaired by the increasing contingent of citrus fruits produced on the southern hemisphere being equally variable also because of the fate of concentrates held in stocks. The idea of double purpose apple growing (higher quality for fresh consumption and lower quality for industrial processing in the same plantation) has to be considered in relation with the growing system. The majority of plantations are extensive or semi-intensive, i.e. of the traditional type. The trees are relatively large; the planting design is different. In those trees, the manual labour necessary for producing large fruit (e.g. thinning) cannot be performed, and the price of the processing type apple would not allow it, but also for the regular yields it would be necessary. Alternating of yield is inevitably more severe in those orchards, which is an additional handicap of the industrial apple.

It's unequivocal that the price of apple for juice will remain low (10-20 Ft/kg). China produces - as earlier explained $-30 \%$ of the world's apple juice at very costs, and this is decisive. Similarly, Poland's role is the same in Erurope with 1.5-2.0 million tons of apple.

The low prices do not allow the processing apple growing to be economical. No variety, no technology exists, which may save the branch against extinction. Another proof of the fact is the attempt of the growers to sell apple for fresh consumption, which means about $(30-50 \%)$ of the yield. Without that, the lowest price for the apple being lucrative were 30-40 Ft/kg, which has very little chances over many years.

We have to state that the majority of apple for processing is grown in older plantations (cca. 13000 hectares) with low yields (5-15 t/ha), meaning that the economical expectations are and will be very poor. The boldest hopes postulate the possibly minimum of costs, and utilisation of dependants without wage in order to raise some income. Most of those plantations are incapable to compete nay to survive, and should be earlier or later cleared. Nota bene, the chances to replace those plantations are low too. The apple growing area ought to be reduced anyway.

The fate and decline of the apple growing area, however, should not be reflected on the entire fruit-growing branch, because the adverse processes are not uniformly hitting every enterprise. There have been always successful entrepreneurs, who are not by all odds provided with capital (supposedly a minority), but many of them will abandon the profession.

Earlier analyses prove that the economy of growing apple for fresh consumption in not doomed to fail in Hungary, because plantations with up to date equipment and technology produce a high rate of the desired quality (85-91\%) and cope with the competitive Western growers (German and Italian). This category is, however, represented by $8-10 \%$ of the branch (3-4 thousand hectares). It should be emphasised that at the present producer's prices $(70-80 \mathrm{Ft} / \mathrm{kg}$ ) the minimum yields for being successful ought to be around 40-50 t/ha.
The tightening conditions of competition, increasing number of concurrents will hit not only the growers supplying apple juice, but also the enterprises striving for higher quality, i.e. apple for fresh consumption, using intensive technologies. The advantages, which should be exploited (against the West European concurrence), are summarised in the three points:

- at present and in the not very near future, manual labour is cheaper and the wages are lower by $60-80 \%$,

- subventions of investments are more intense by $15-30 \%$,

- Hungarian enterprises are supposedly less threatened by hails and may economise the costly investment for antihail nets.

These advantages are nevertheless of a temporary nature and are independent from the skill of growers! Wages may be raised, subventions expire and climatic changes are expected (being experienced in 2007 spring frosts and hails in the past two years). Costs of production will increase by all means, and we have to be prepared to it. Our advantages will gradually diminish. In addition, in the majority of years, the price of apple for fresh consumption was depressed very much - mainly during the autumn and winter months. The producer's price level is lower in Hungary by $20-40 \%$ than in Germany and Italy. Regarding the future tendencies, the prices will not increase as they did neither in Italy nor in Germany during the last 10 years, but rather diminish.

Summing up the arguments, according our best conviction, the aims of development should not prefer the growing of industrial apple neither the double purpose apple growing, but clearly, that of apple for fresh consumption with a quality approaching $100 \%$ as being the only reasonable target all around the world.

The possibilities of developing the apple industry are not boundless neither for fresh consumption. The present consumption in Hungary is $15-20 \mathrm{~kg} /$ year per capita; taking a population of 10 million, 150-200 thousand tons are needed. Adding the volume of a possible export and subtracting the imported one, the result, valid for the next 5-10 year period, about 200-300 thousand tons of apple for fresh consumption is calculated. That quantity could be produced on a surface of 10 thousand hectares taking a yearly mean of $30-40 \mathrm{t} / \mathrm{ha}$ because the risk of weather anomalies and phytosanitary accidents are threatening the production.

All those arguments are also projected into the future of long run. The present extension of the apple branch being 35000 hectares will be reduced to 15-20 thousand - for both, apple for fresh consumption as well as for processing. All that will ensue in the near future, i.e. during the next decennium.

\section{Possible solutions}

Before going into details we attempted to enumerate the main causes of the problems showing up in the fate of the apple-growing branch:

- The high rate of neglected and ill treated plantations associated with the non-objective interpretation of 
quality. The consequence is the low quality appearing on the market. The presence of large volumes of low quality apple depresses the producer's price of the high quality apple.

- Insufficiency of storing capacity of the country, consequently, the sale after harvest is urgent, which produces a buyer's market with low prices and symptoms of overproduction appear.

- Insufficiency of producer's organisations on the market (TÉSZ organisations), which is confronted with the highly organised world of the trade and the processing industry. Individual growers are in a disadvantageous position; their safeguarding of interests is poorly represented, which is a serious handicap in bargaining on a market showing symptoms of overproduction. (The consequences coupled with that of the former point deliver the growers to the fate of looser in the business). The characteristic consequence is also that shopkeepers enjoy the most favourable position within the path of apple trade.

- Production is divided into little bits, whereas the processes of the market are incomprehensible (small farms, hectic production, poor statistics and information regarding prices). Orientation on the market is difficult, possibility a fraud is high.

- The complete lack of management, leadership and coordination within the branch, "activities supporting the production". (extension service, forecasts in phytosanitation, weather, alarming, information of market prices, etc.). The low level of prices is the direct cause of disinterestedness of the society, which is a common feature and claim of the western everyday decision-making.

After having dealt with the causes, we present our suggestions as follows:

- As the subvention of clearing obsolete plantations is not accepted, we have to approach the question from the side of punishing sanctions. The market should be cleaned from the offer of poor quality apple, which will raise the producer's prices. The basis of the sanctions will be formulated in a brochure, the Right Practice of Husbandry", where a system of requisites is elaborated and a severe control introduced.

- Severe supervision of consumer's protection must be introduced in order to clean the shelf of shops from the fruits of low quality (more severe than actual). Also the imported apple should be controlled more severely.

- The storing capacity should be increased substantially. The subventions ought to be concentrated for that purpose.

- A key question is the development of the producer's organisations. I.e. the system of TÉSZ organisations with adequate capacities for bargaining on the market.
- The hectic and chaotic markets should be transformed to a clearly arranged system, where the development of a service monitoring the variation of prices will provide information for the participants. All that would mean little costs. Details are not dealt with here.

- In order to defend the interests, producers' organisations ought to be established, and an alliance of councils of production encouraged up to the point, until the concentration of wealth will correspond to expectations.

- For all those purposes, the starting of producerssupporting activities is to be designed: weather forecast, phytosanitary information and alarming systems, extension service for spreading professional-technical innovations, juridical actualities, etc. In Western Europe, those institutions have vital traditions and are elementary claims.

- An important condition of keeping the position on the market is the continuous presence and aid of capacities involved in research and development. Innovations are everyday opportunities of the economical life being conditions of competitiveness.

- For the extension of our markets, we ought to concentrate activities on the care of domestic consumption and, as a next step, to large countries of the neighbourhood (Russia, Ukraine, Romania), where the relatively shorter distance is an advantage in relation to Western Europe, which could be exploited. All that anticipates a thoughtful program of marketing, which should be started soon.

- The development of effectiveness from the point of view of costs and incomes is doomed to move between narrow boundaries. The main components are nevertheless marked as increasing productivity, the security and quality of yields (as far as being influenced by the growers).

- A potent improvement of effectiveness could be achieved from the side of the costs of production. After increasing of the size of enterprises, the next and potent source of development is the subvention of investments for apple plantations. The producer's price could be reduced by that way with $10-12 \mathrm{Ft} / \mathrm{kg}$ i.e. $20-25 \%$.

- Our temporary advantage of relatively low wages for manual labour compared with Western Europe should be maintained and exploited by regulating the system of employment and adapting it to the claims of horticultural production.

The realisation of the above mentioned suggestions would be the issue of improving the fate of the apple-growing branch. A thoughtful elaboration of a strategy is badly needed, which unequivocally qualifies the participants of the market, dooming one part to be abolished and the other part to attain prosperity. Trends of development ought to be decided on the basis of considering the complex of causes according to their weight. 